\title{
3D LGE imaging of the LV short axis stack using spiral readouts at $3 \mathrm{~T}$
}

\author{
lain Pierce ${ }^{1,2^{*}}$, Jennifer Keegann ${ }^{2,1}$, Peter Drivas ${ }^{2}$, David Firmin ${ }^{1,2}$ \\ From 17th Annual SCMR Scientific Sessions \\ New Orleans, LA, USA. 16-19 January 2014
}

\section{Background}

Clinical assessment of the viability of myocardium is commonly performed using 2D breath-hold late gadolinium enhancement (LGE) imaging with Cartesian $\mathrm{k}$-space coverage and data acquisition windows (AWs) ranging from 140-200 ms. More efficient k-space coverage using spiral trajectories could allow improved spatial resolution and reduced AWs without greatly extending acquisition durations. To this end, we have developed a navigator-gated spiral 3D LGE sequence and present the results in 10 patients attending for clinical 2D LGE imaging on a 3T Siemens Skyra scanner.

\section{Methods}

The navigator-gated 3D sequence consisted of a stack of spirals (acquired: $8 \mathrm{kz}$ at $1.4 \times 1.4 \times 10 \mathrm{~mm}$, reconstructed: 16 slices at $0.7 \times 0.7 \times 5 \mathrm{~mm}$ ). Each spiral readout was $10 \mathrm{~ms}$ long with 16 interleaves required to fill kx-ky space. All $8 \mathrm{kz}$ for a given spiral interleaf were acquired in a single cardiac cycle (AW $=88 \mathrm{~ms})$. Acquisition duration was 34 cardiac cycles assuming $100 \%$ respiratory efficiency (alternate R-wave gating). 3D imaging was performed after the acquisition of a stack of conventional clinical breathhold 2D LGE images in 10 patients (acquired resolution: $1.4 \times 1.8 \mathrm{~mm}$ reconstructed to $0.7 \times 0.7 \mathrm{~mm}$ ). The $2 \mathrm{D}$

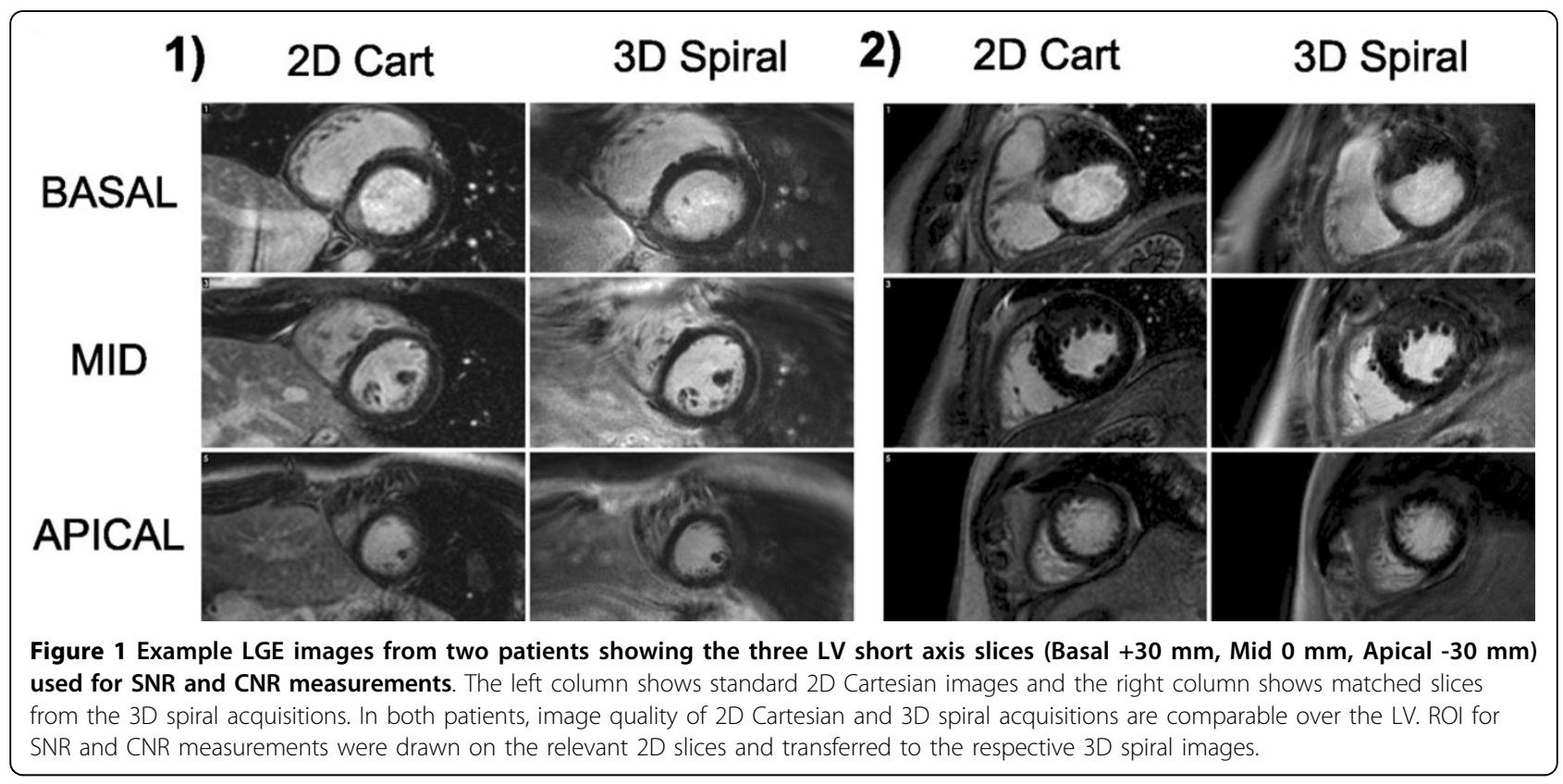

${ }^{1} \mathrm{NHLI}$, Imperial College London, London, UK

Full list of author information is available at the end of the article 

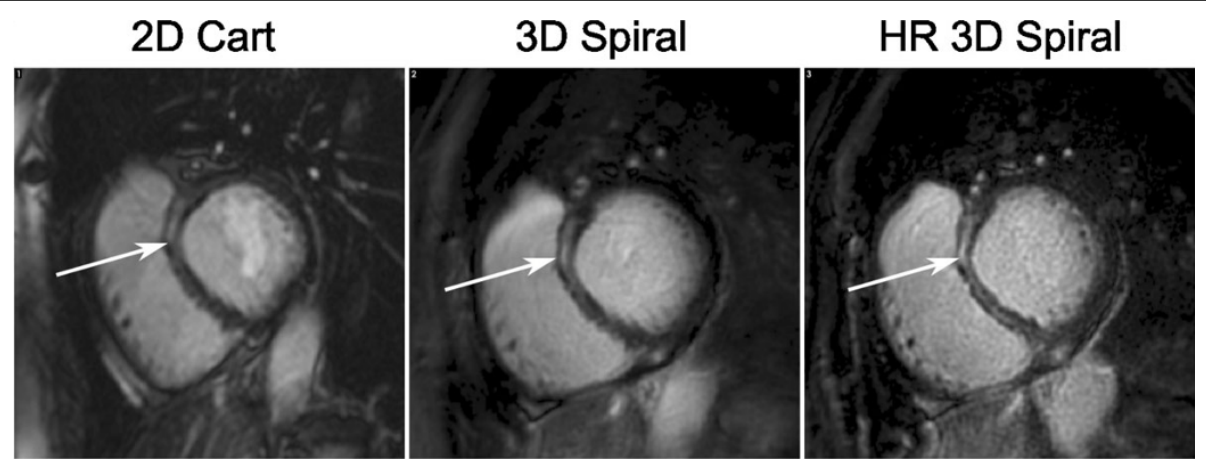

Figure 2 Images of the Basal slice from a third patient showing enhancement in the septum (arrowed). From left to right the images are from the 2D Cartesian, 3D spiral and a higher through plane resolution (HR - 16 $\times 1.5 \mathrm{~mm}$ slices) scans. The higher resolution scan shows better definition of the enhanced region in the mid wall.

images had slice thickness of $7 \mathrm{~mm}$ with slice gap of $3 \mathrm{~mm}$. Acquisition duration was 14 cardiac cycles per slice (alternate R-wave gating). LV blood SNR and bloodmyocardium CNR in conventional 2D and spiral 3D scans were compared in 3 matched slices (basal, mid and apical) using paired Wilcoxon signed rank test.

\section{Results}

SNR measurements were significantly higher and CNR were borderline significantly higher for the 3D spiral compared to the 2D scans (SNR: $10.96 \pm 2.71$ vs $13.59 \pm 4.70$ $(\mathrm{p}<0.01)$; CNR: $9.23 \pm 2.60$ vs $10.52 \pm 4.00(\mathrm{p}=0.06)$ ). Figure 1 shows images from 2 example patients. Image quality over the LV is similar for 2D Cartesian and 3D spiral acquisitions although some off-resonance blurring can sometimes be seen in the spiral acquisitions, despite the short spiral readout durations (e.g. inferolateral wall of the RV in patient 1 ). This may be improved using spatially varying off-resonance correction. Figure 2 shows basal slices from a patient with enhancement in the septum which is more defined on the 3D spiral image due to better through-plane resolution and a reduced AW. A higher through-plane resolution 3D spiral image is also shown for comparison. Spiral 3D scans had mean acquisition duration $83 \mathrm{~s}$ (51-144 s), allowing for multiple repetitions or high resolution examination of regions of enhancement in similar duration as the 2D stack with 8 slices taking $\sim 240 \mathrm{~s}$; shorter AWs may also have reduced motion blurring.

\section{Conclusions}

Navigator-gated 3D spiral LGE imaging allows contiguous coverage of the LV with higher spatial resolution, shorter acquisition windows and reduced acquisition durations when compared to a stack of conventional breath-hold 2D LGE Cartesian acquisitions.

\section{Funding}

Wellcome Trust Grant WT093953MA NIHR - National Institute for Health Research.

\section{Authors' details}

${ }^{1} \mathrm{NHLI}$, Imperial College London, London, UK. ${ }^{2}$ Cardiovascular BRU, Royal Brompton Hospital, London, UK.

Published: 16 January 2014

doi:10.1186/1532-429X-16-S1-P8

Cite this article as: Pierce et al:: 3D LGE imaging of the LV short axis stack using spiral readouts at 3T. Journal of Cardiovascular Magnetic Resonance 2014 16(Suppl 1):P8.
Submit your next manuscript to BioMed Central and take full advantage of:

- Convenient online submission

- Thorough peer review

- No space constraints or color figure charges

- Immediate publication on acceptance

- Inclusion in PubMed, CAS, Scopus and Google Scholar

- Research which is freely available for redistribution

Submit your manuscript at www.biomedcentral.com/submit
Bïmed Central 